\title{
Endothelin-1 (ET-1) Selectively Enhances the Activation Gating of Slowly Inactivating Tetrodotoxin-Resistant Sodium Currents in Rat Sensory Neurons: A Mechanism for the Pain-Inducing Actions of ET-1
}

\author{
Zhongren Zhou, ${ }^{1 *}$ Gudarz Davar, ${ }^{*}$ and Gary Strichartz ${ }^{1,2}$ \\ 1 Pain Research Center, Department of Anesthesiology, Perioperative and Pain Medicine, Brigham and Women's Hospital, \\ and 2 Department of Biological Chemistry and Molecular Pharmacology, Harvard Medical School, Boston, Massachusetts \\ 02115
}

Endothelin-1 (ET-1) causes pain through activation of nociceptors, by either direct depolarization or increased excitability. Here we examined the effect of ET-1 on nociceptor-associated tetrodotoxin-resistant (TTX-R) sodium currents using wholecell voltage clamp of acutely dissociated rat dorsal root ganglion (DRG) neurons. DRG neurons that responded had enhanced activation gating when exposed to $10 \mathrm{~nm} E T-1$, as determined by significant shifts in their average activation midpoint potentials $\left(\Delta E_{0.5}=-8.0 \pm 0.5 \mathrm{mV}\right)$ when compared with control $\left(\Delta E_{0.5}=-2.2 \pm 0.4 \mathrm{mV} ; n=6\right)$ and $\mathrm{ET}-1$ unresponsive cells $\left(\Delta E_{0.5}=-3.2 \pm 0.2 \mathrm{mV}\right)$. ET- 1 also modified the availability of TTX-R channels, as determined by negative shifts in the average midpoint potential for inactivation of ET-1 responsive cells when compared with controls. These actions of ET-1 occurred predominantly in cells with more slowly inactivating
TTX-R currents. Both time-to-peak current and inactivation time constants were shortened by ET-1 in responsive cells. Previous exposure of cells to the endothelin- $A\left(E T_{A}\right)$ receptor antagonist BQ-123 (1 $\mu \mathrm{M})$ prevented ET-1-induced shifts in TTX-R activation. In contrast to changes in TTX-R, ET-1 did not modify tetrodotoxin-sensitive currents recorded from DRG neurons. These results demonstrate that the algogenic peptide ET-1 induces $\mathrm{ET}_{\mathrm{A}}$ receptor-mediated, hyperpolarizing shifts in the voltage-dependent activation of TTX-R Na ${ }^{+}$channels, a potential mechanism for selective excitation by ET-1 of nociceptors that we observed in vivo.

Key words: nociception; excitability; G-protein-coupled receptor; sodium channel; hyperalgesia, dorsal root ganglion neurons
Endothelin-1 (ET-1) is a potent vasoconstrictor peptide that has been implicated in the pathogenesis of tissue inflammation and pain (Ferreira et al., 1989; Piovezan et al., 1997; Davar et al., 1998; De-Melo et al., 1998; Graido-Gonzalez et al., 1998; Griswold et al., 1999; Fareed et al., 2000; Jarvis et al., 2000; Wacnik et al., 2001). Recent results from our laboratory suggest that the pain-inducing actions of ET-1, which include the induction of firing in peripheral nociceptors (Gokin et al., 2001), are attributable to direct actions on these cells rather than secondary to any vasoactive effect (Zhou et al., 2001). ET-1 might excite nociceptors by activating or potentiating an inward current or by suppressing an outward current that contributes to the resting potential. Indeed, a tetrodotoxin-resistant (TTX-R) voltage-gated $\mathrm{Na}^{+}$current in human cardiac tissue $\left(\mathrm{hH} 1, \mathrm{Na}_{\mathrm{V}} 1.5\right)$ is known to be enhanced by ET-1 (Cheng et al., 1995). In nociceptive neurons, TTX-R channels have been implicated in the increased sensitivity to pain that follows tissue inflammation and are believed to play a critical role in sensory neuronal excitability (Gold et al., 1996; England et al., 1996; Renganathan et al., 2001). Furthermore, the modulation of TTX-R currents by the injury-related mediators

\footnotetext{
Received March 20, 2002; revised May 13, 2002; accepted May 17, 2002.

*Z.Z. and G.D. contributed equally to this work.

Correspondence should be addressed to Dr. Gudarz Davar, Molecular Neurobiology of Pain Laboratory, Pain Research Center, Department of Anesthesiology, Perioperative and Pain Medicine, Brigham and Women's Hospital, 75 Francis Street, Boston, MA 02115. E-mail: gdavar@zeus.bwh.harvard.edu.

Copyright (C) 2002 Society for Neuroscience 0270-6474/02/226325-06\$15.00/0
}

prostaglandin E2, adenosine, and serotonin (Gold et al., 1998; Cardenas et al., 2001) has been shown to depend on neuronal protein kinases, which produce long-lasting changes that might underlie the prolonged firing that we induce in nociceptors with ET-1.

The possible contribution of enhanced TTX-R currents to ET-1-induced nociception has not been examined. Therefore, in these experiments, we examined the effect of ET-1 on early and late TTX-R and tetrodotoxin-sensitive (TTX-S) sodium currents in acutely dissociated rat dorsal root ganglion (DRG) neurons using whole-cell voltage clamp. We also determined the receptordependence of the actions of ET-1 on TTX-R currents and analyzed the TTX-R activation and inactivation gating.

\section{MATERIALS AND METHODS}

Cell preparation. DRGs were harvested from male Sprague Dawley rats (150 gm; Charles River, Wilmington, MA) as described previously (Gold et al., 1998). Rats were anesthetized with Na pentobarbital (Nembutal; 60 mg/kg, i.p.; Parke-Davis Courbevoie, France). Lumbar DRGs (L1L6) were removed and treated with $0.125-0.25 \%$ collagenase (Boehringer Mannheim, Indianapolis, IN) and $0.25 \%$ (w/v) trypsin (Worthington, Freehold, NJ) in ice-cold complete modified Eagle's medium (MEM) composed of 90\% MEM (Invitrogen, Grand Island, NY) and $10 \%$ fetal bovine serum (Invitrogen). Cells were plated and incubated at $37^{\circ} \mathrm{C}$ with $5 \% \mathrm{CO}_{2}$ and then transferred to a $27^{\circ} \mathrm{C}$ incubator with $5 \%$ $\mathrm{CO}_{2}$. Cells were used between 2 and $24 \mathrm{hr}$ after this final plating.

Electrophysiology. The whole-cell voltage-clamp technique was used to measure $\mathrm{Na}^{+}$currents, using borosilicate glass electrodes (World Precision Instruments, Sarasota, FL). The resistance of electrodes pulled by a 
P-87 Electrode Puller (Sutter Instruments, Novato, CA) ranged from 0.8 to1.5 M $\Omega$. Voltage clamp was controlled by an Axopatch-200 (Axon Instruments, Foster City, CA), and currents, initially filtered at $10 \mathrm{kHz}$, were collected using pClamp8 software (Axon Instruments). Series resistance (1-4 M $\Omega$ ) and capacitance were partially compensated electronically. Leak and residual capacity currents were subtracted using the P/4 procedure (Armstrong and Bezanilla, 1977).

Solutions and drugs. Synthetic ET-1 (98\% pure peptide content) and BQ-123 were both obtained from American Peptides (Sunnyvale, CA) and were dissolved in PBS (Invitrogen), $\mathrm{pH} 7.4$, before use. TTX was obtained from Sigma (St. Louis, MO). The patch electrodes were filled with the following (in mM): $130 \mathrm{CsF}, 3 \mathrm{MgATP}, 0.5 \mathrm{LiGTP}, 3 \mathrm{MgCl}_{2}, 5$ $\mathrm{NaCl}, 1.1$ EGTA, $0.1 \mathrm{CaCl}_{2}$, and 10 HEPES, pH 7.2. The bath solution for recording TTX-R currents contained the following (in $\mathrm{mM}$ ): $35 \mathrm{NaCl}$, 75 choline-Cl, 30 TEA-Cl, $5 \mathrm{KCl}, 1 \mathrm{CaCl}_{2}, 10$ glucose, $1 \mathrm{MgCl}_{2}$, and 10 HEPES, pH 7.4. To isolate TTX-R Na currents, TTX $(0.1 \mu \mathrm{M})$ was used in all experiments, except those used to measure TTX-S. In these latter experiments, low $\mathrm{Na}^{+}(5 \mathrm{mM})$ was used (with the difference substituted by equimolar choline chloride) to avoid saturation of the amplifier with the large TTX-sensitive currents found primarily in large-diameter cells.

\section{RESULTS}

\section{ET-1 modifies peak activation of TTX-R currents in a subpopulation of sensory neurons}

Tetrodotoxin-resistant sodium currents were recorded in 17 DRG cells exposed to $10 \mathrm{~nm}$ ET-1. These currents had voltagedependent kinetics nearly identical to those reported previously for TTX-R in sensory neurons (Bossu and Feltz, 1984; Gold et al., 1996; Rush et al., 1998), and the peak current showed a reversal potential $(+40.2 \pm 1.7 \mathrm{mV})$ that was close to the calculated equilibrium potential for sodium ions under these conditions. In 10 of these small cells (capacitance, $23.8 \pm 1.3 \mathrm{pF}$ ), the "activation gating" of peak $\mathrm{Na}^{+}$current was enhanced, as determined by negative shifts along the voltage axis of the peak conductance versus test potential (Fig. 1). In seven cells of similar size, activation gating was unchanged compared with changes in control cells (see below; Table 1). Such gating represents the voltagedependent probability that $\mathrm{Na}^{+}$channels will open in response to rapid membrane depolarization and is closely linked to membrane excitability. Gating modifications developed over 2-5 min, consistent with $\mathrm{Na}^{+}$channel modifications initiated by other G-protein-coupled receptors in DRG neurons (Gold and Levine, 1996), and reached a steady-state by $10 \mathrm{~min}$, when the shifts were analyzed. The criteria for a real change in such gating was based on comparison with the spontaneous changes that occurred in the absence of ET-1; activation midpoint potentials $\left(E_{0.5}\right)$ and slopes $(k)$ calculated from fits of the Boltzmann equation to the conductance data (Fig. 1D) (cf. Hille, 2001) in these control cells had initial values that were not changed after 10 or $20 \min (n=4)$ in control medium. Thus, the seven cells with insignificantly different changes produced by ET-1 were classified as "unresponsive" (range, -1.9 to $-3.9 \mathrm{mV} ; p>0.05$; unpaired $t$ test) (Fig. 2). In contrast, the 10 ET-1 "responsive" cells had highly significant average shifts of $E_{0.5}$ (range, -4.1 to $-11.7 \mathrm{mV}$ ) when compared with baseline values ( $p=0.0003$; paired $t$ test $)$ and with the control group ( $p=0.0004$; unpaired Student's $t$ test). All 10 responsive cells had $\Delta E_{0.5}$ that were greater than $-4 \mathrm{mV}$ (Fig. 2), whereas none of the unresponsive cells had changes of that magnitude (Fig. 2). Changes of the activation slope, $k$, that occurred spontaneously or during exposure to ET-1 were not significant $(p>0.46)$. ET-1 also shifted the reversal potential $\left(E_{\mathrm{rev}}\right)$ slightly but significantly (from $+38.7 \pm 1.7$ to $+34.9 \pm 1.9$ $\mathrm{mV} ; p=0.03$ ) in responsive but not in unresponsive or control cells, possibly consistent with actions of ET-1 on other, likely outward, ionic currents flowing at these positive voltages.

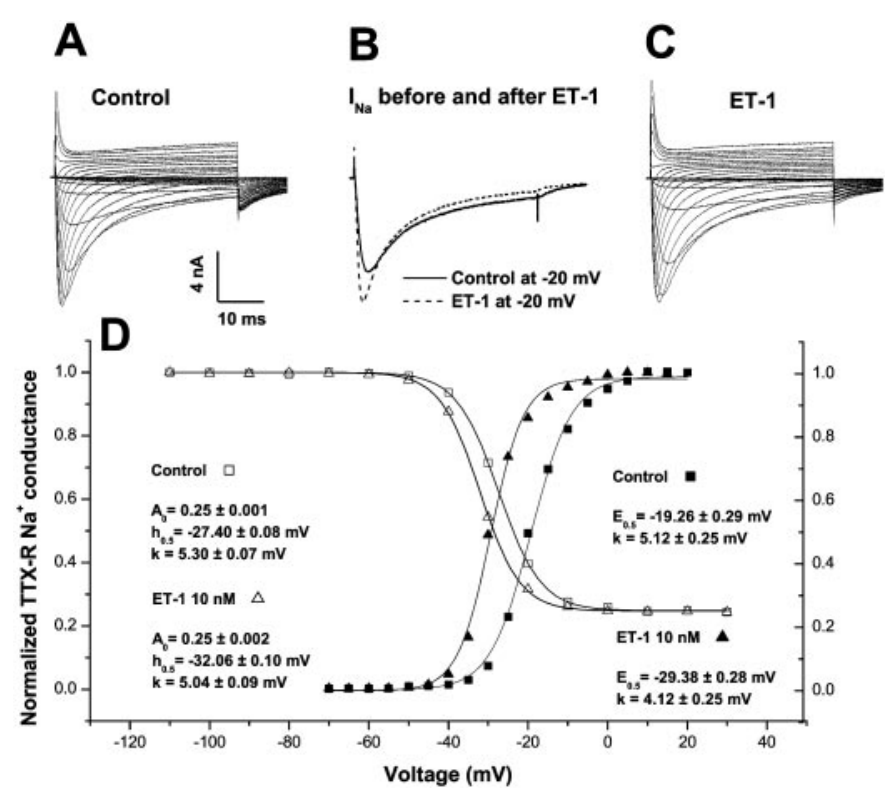

Figure 1. Changes in $\mathrm{Na}^{+}$current gating induced by ET-1. $A$, A control family of TTX-R currents recorded during the sequential application of 40 -msec-long test depolarizations, ranging from -70 to $+30 \mathrm{mV}$ in $5 \mathrm{mV}$ steps, in a small-diameter DRG neuron. $E_{\text {hold }}=-80 \mathrm{mV} ; f_{\text {test }}=0.1 \mathrm{~Hz}$; $T=20-22^{\circ} \mathrm{C}$; TTX $=100 \mathrm{~nm}$. B, TTX-R currents during a $-20 \mathrm{mV}$ depolarization recorded before and 10-12 min after exposure to $10 \mathrm{~nm}$ ET-1 in the same cell as that in $A$. $C$, A family of TTX-R currents recorded from the same cell and under the same conditions as in $B . D$, Analysis of the voltage dependence of peak conductance activation ( filled symbols) and availability (inactivation; open symbols) before (squares) and 10-12 min after (triangles) exposure of one cell to ET-1 (10 nM). Current data are from the same cell described in $A-C$. Fits of the Boltzmann equation to the peak conductance versus test depolarization data yield values for the activation midpoint potential $\left(E_{0.5}\right.$, with $95 \%$ confidence limits from this single fit) that are shifted by $-10 \mathrm{mV}$ in this cell. Availability (inactivation) parameters were generated from Boltzmann functions fit to normalized, inactivatable peak current versus prepulse (100-msec-long) potential data, from a different cell than the one yielding the activation data. The non-inactivatable TTX-R remained at $\sim 0.25$ of the total current after ET-1 exposure, whereas the midpoint potential for availability $\left(h_{0.5}\right)$ was shifted by $-5 \mathrm{mV}$ in this cell. The slope factors, $k$, for activation and for availability functions were not changed by ET- 1 .

\section{ET-1 also changes inactivation of TTX-R in sensory neurons}

Steady-state inactivation (availability) of TTX-R Na ${ }^{+}$channels was also modified by ET-1. This parameter indicates the fraction of $\mathrm{Na}^{+}$channels that is poised to open in response to a rapid depolarization, a key index to the resting excitability of the membrane that is regulated through the resting potential. In 10 ET-1 responsive cells, all showing shifts of activation gating (see above), the midpoint potential for inactivation, $h_{0.5}$ (determined from the amplitudes of currents during a test pulse to $-10 \mathrm{mV}$ after $100 \mathrm{msec}$ prepulses ranging from -120 to $+30 \mathrm{mV}$ ), was negatively shifted by $5 \mathrm{mV}$ after a $10 \mathrm{~min}$ exposure to $10 \mathrm{~nm}$ ET-1 (Table 1, Fig. 1D). Four control cells, untreated by ET-1, had spontaneous changes over this same time course in $h_{0.5}$ of $-0.92 \pm 0.09$, significantly less than the changes with ET- 1 in responsive cells $(p=0.0011)$. In ET-1 unresponsive cells, there was a smaller inactivation shift of $-2.2 \mathrm{mV}$ compared with control $(p=0.0017)$ and responsive $(p=0.019)$ cells. Treatment by ET-1 did not alter the fraction of TTX-R channels that did not inactivate in $100 \mathrm{msec}$, which remained at $\sim 25 \%$ (Fig. 1, $A_{o}$ ), nor did it change the slope factor, $k_{\mathrm{h}}$, of inactivation. The kinetics of this remaining, non-inactivatable current showed the same acti- 
Table 1. Effect of ET-1 on activation and inactivation of TTX-R and TTX-S sodium channels in rat DRG neurons

\begin{tabular}{|c|c|c|c|c|}
\hline & \multicolumn{2}{|c|}{ Activation curve* } & \multicolumn{2}{|c|}{ Availability curve** } \\
\hline & $E_{0.5}(\mathrm{mV})$ & $k_{\mathrm{a}}(\mathrm{mV})$ & $h_{0.5}(\mathrm{mV})$ & $k_{\mathrm{h}}(\mathrm{mV})$ \\
\hline \multicolumn{5}{|l|}{ TTX-R } \\
\hline \multicolumn{5}{|l|}{ Control cells $(n=6)$} \\
\hline Baseline & $-14.49 \pm 1.29$ & $5.59 \pm 0.72$ & $-24.75 \pm 0.44^{\mathrm{a}}$ & $4.76 \pm 0.02$ \\
\hline $10 \min$ & $-16.67 \pm 1.35$ & $6.13 \pm 0.70$ & $-25.67 \pm 0.53$ & $5.29 \pm 0.00$ \\
\hline $20 \mathrm{~min}$ & $-14.11 \pm 0.87$ & $5.95 \pm 0.67$ & & \\
\hline$\Delta[10 \mathrm{~min}-$ baseline $]$ & $-2.17 \pm 0.42$ & $1.03 \pm 0.54$ & $-0.92 \pm 0.09$ & $0.53 \pm 0.02$ \\
\hline \multicolumn{5}{|l|}{ ET- 1 responsive cells $(n=10)$} \\
\hline Baseline & $-18.94 \pm 1.42$ & $5.39 \pm 0.25$ & $-27.26 \pm 1.48$ & $5.33 \pm 0.10$ \\
\hline ET-1 & $-26.98 \pm 1.34$ & $4.64 \pm 0.27$ & $-32.44 \pm 1.50$ & $6.02 \pm 0.29$ \\
\hline$\Delta[$ ET-1 - baseline $]$ & $-8.04 \pm 0.54$ & $0.75 \pm 0.27$ & $-5.18 \pm 0.37$ & $0.69 \pm 0.26$ \\
\hline \multicolumn{5}{|l|}{ ET-1 non-responsive cells $(n=7)$} \\
\hline Baseline & $-13.33 \pm 2.20$ & $5.93 \pm 0.45$ & $-20.57 \pm 0.35^{\mathrm{b}}$ & $5.33 \pm 0.03$ \\
\hline ET-1 & $-15.58 \pm 2.34$ & $4.64 \pm 0.27$ & $-22.81 \pm 0.38$ & $5.93 \pm 0.04$ \\
\hline$\Delta[$ ET-1 - baseline $]$ & $-3.25 \pm 0.18$ & $0.07 \pm 0.17$ & $-2.24 \pm-0.03$ & $0.60 \pm 0.03$ \\
\hline \multicolumn{5}{|c|}{ BQ-123 plus ET-1-treated cells $(n=10)$} \\
\hline Baseline & $-10.27 \pm 1.85$ & $6.67 \pm 0.36$ & $-23.55 \pm 1.85$ & $6.41 \pm 0.34$ \\
\hline BQ-123 & $-12.34 \pm 1.84$ & $5.94 \pm 0.37$ & $-25.12 \pm 2.02$ & $6.51 \pm 0.56$ \\
\hline BQ-123 plus ET-1 & $-13.93 \pm 1.90$ & $6.13 \pm 0.24$ & $-29.05 \pm 2.11$ & $6.63 \pm 0.38$ \\
\hline$\Delta[\mathrm{BQ}-123$ - baseline $]$ & $-2.07 \pm 0.61$ & $1.54 \pm 0.45$ & $-1.85 \pm 0.50$ & $0.13 \pm 0.30$ \\
\hline$\Delta[(\mathrm{BQ}-123+\mathrm{ET}-1)-\mathrm{BQ}-123]$ & $-1.54 \pm 0.45$ & $0.19 \pm 0.17$ & $-2.90 \pm 0.35$ & $0.07 \pm 0.26$ \\
\hline \multicolumn{5}{|l|}{ TTX-S $(n=7)$} \\
\hline Baseline & $-14.49 \pm 1.29$ & $5.59 \pm 0.72$ & $-24.75 \pm 0.44$ & $4.76 \pm 0.02$ \\
\hline ET-1 & $-16.67 \pm 1.35$ & $5.95 \pm 0.67$ & $-25.67 \pm 0.53$ & $5.29 \pm 0.01$ \\
\hline$\Delta[$ ET-1 - baseline $]$ & $-2.17 \pm 0.42$ & $1.03 \pm 0.54$ & $-0.92 \pm 0.09$ & $0.53 \pm 0.02$ \\
\hline
\end{tabular}

All values listed are means \pm SEM. *Boltzmann equation for fitting the activation curve is as follows: $G / G_{\max }=\left\{1+\exp \left[-\left(E-E_{0.5}\right) / k_{\mathrm{a}}\right]\right\}^{-1}$. **Boltzmann equation for fitting the availability curve is as follows: $I / I_{\max }=\left(A_{\max }-A_{0}\right) /\left\{1+\exp \left[\left(h_{0.5}-E\right) / k_{\mathrm{h}}\right]\right\}+A_{0}$.

$a_{n}=4$.

${ }^{b} n=4$.

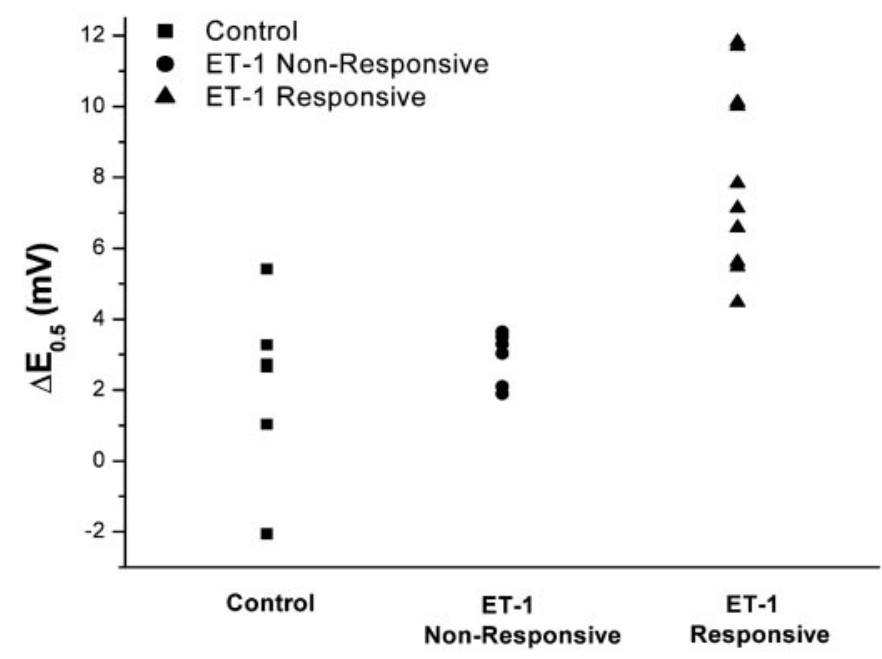

Figure 2. Scattergram showing the distribution of changes in activation midpoint potentials $\left(\Delta E_{0.5}\right)$ of individual DRG neurons unexposed to ET-1 (Control; changes after $10 \mathrm{~min}$ ), exposed to ET-1 but with $\Delta E_{0.5}<$ $-4 \mathrm{mV}$ after $10 \mathrm{~min}$ (ET-1 Non-Responsive), and exposed to ET-1 and having $\Delta E_{0.5}>-4 \mathrm{mV}$ after $10 \mathrm{~min}$ (ET-1 Responsive).

vation rise and time-to-peak as the total current, consistent with its assignment as a non-inactivating $\mathrm{Na}^{+}$current.

\section{Sensitivity to ET-1 is related to $\mathrm{Na}^{+}$current kinetics}

The degree of change of $\mathrm{Na}^{+}$current by ET- 1 in responsive cells depended on the baseline gating kinetics of the $\mathrm{Na}^{+}$currents, and these kinetics, in turn, were modified by ET-1. Currents that were predominantly transient, fast inactivating (with a decay time constant, $\tau$, of $\sim 10 \mathrm{msec}$ or less at $-20 \mathrm{mV}$ ) were altered less by ET-1; peak current amplitude at $-20 \mathrm{mV}$ was increased $1.17 \pm$ 0.11 -fold in three such cells. In contrast, currents that inactivated more slowly $(\tau>14 \mathrm{msec})$ were amplified more strongly by ET-1 $(5.3 \pm 3.5$-fold $)$. In fact, there was a significant correlation $\left(r^{2}=\right.$ $0.81 ; p<0.002$ ) between the control inactivation $\tau$ and the degree of ET-1-induced amplification of peak current.

The "late" $\mathrm{Na}^{+}$currents, measured at the end of the 40-mseclong depolarization, had a reversal potential of $3.9 \pm 2.5 \mathrm{mV}$, indicating that they are a mixture of $\mathrm{Na}^{+}$currents and another outward current. The contributions from $I_{\mathrm{Na}}$ represent the open probability of subpopulations of channels that either close very slowly or maintain a low-level, persistent activation during sustained depolarization (Cummins et al., 1999). Activation functions for the late components of TTX-R, analyzed from currents averaged over the 35-40 $\mathrm{msec}$ at the end of the test depolarizations (Fig. $1 A, C$ ), were fit by the Boltzmann equation with $E_{0.5}=$ $-27.4 \pm 7.4 \mathrm{mV}$ and $k=3.5 \pm 0.6 \mathrm{mV}$ before ET-1; the same respective parameters were changed by $-6.43 \pm 0.04(p=0.002)$ and $-0.49 \pm 1.5 \mathrm{mV}(p=0.4)$ after ET-1 treatment in the responsive cells, very similar to the $-8 \mathrm{mV}$ shift of the peak $\mathrm{Na}^{+}$ conductance (see above). These results are consistent with a selective action of ET-1 on the non-inactivated $\mathrm{Na}^{+}$currents at this time rather than an alteration of other "contaminating" currents.

Although there was a difference in the baseline midpoint po- 
tentials for both activation and availability gating, measured before ET-1 exposure, between the 10 responsive cells and the seven unresponsive cells, this difference did not achieve significance (Table 1) ( $p=0.07$; unpaired $t$ test). These data, together with the similarity in membrane capacitances for these groups of cells, argue against any relevant phenotypic differences in these two populations of neurons.

\section{Gating kinetics are altered by ET-1}

ET-1-induced shifts in $\mathrm{Na}^{+}$conductance were accompanied by a general acceleration of gating kinetics (Fig. $1 B$ ). Currents during a $-20 \mathrm{mV}$ depolarization (near $E_{0.5}$ ) in all responsive cells had a shortened time-to-peak current, to $0.70 \pm 0.06$ of control $(p=$ $0.01)$, and a decreased $\tau$ to $0.66 \pm 0.05$ of control $(p=0.02)$. The currents in cells with faster inactivation rates at the baseline, preexposure condition $(\tau \sim 10 \mathrm{msec})$ had this rate increased insignificantly, by a factor of $1.28 \pm 0.16$ after ET- 1 exposure $(p=0.10)$, whereas in those with the slower baseline decay rate $(\tau>14 \mathrm{msec})$ inactivation was significantly accelerated, by a factor of $2.22 \pm 0.69(p=0.02)$. Interestingly, the maximum $\mathrm{Na}^{+}$ conductance, determined by the limiting slope of the $I_{\mathrm{Na}}$ versus $E_{\mathrm{m}}$ relation at large depolarizations (analysis not shown), was not changed by ET-1; the maximum conductance ratio between treated and control cells equaled $1.043 \pm 0.002$ in 10 responsive cells. This implies that the maximum number of activatable $\mathrm{Na}^{+}$ channels is unchanged by ET-1, although the rapid gating kinetics are altered. In the seven unresponsive cells, the gating kinetics were unchanged by ET-1.

\section{Changes in activation gating are mediated through endothelin-A receptors}

Ten minute treatment of cells modified previously by ET-1 with an antagonist of the endothelin-A $\left(\mathrm{ET}_{\mathrm{A}}\right)$ receptor BQ-123 $(1 \mu \mathrm{M})$, which prevents ET-1-induced behavioral responses and excitation of nociceptive afferents in vivo (Davar et al., 1998; Gokin et al., 2001), did not alter the shift, which grew even more negative during the treatment period (Fig. $3 D)\left(\Delta E_{0.5}=-11.6 \pm 1.3 \mathrm{mV}\right.$ from pre-ET-1 baseline; $n=4)$. Subsequent washing with control media for 10 min was also ineffective $\left(\Delta E_{0.5}=-11.9 \pm 2.5 ; n=\right.$ $3)$. In contrast, pretreatment with BQ-123 (1 $\mu \mathrm{M})$, followed by coexposure with ET-1 (10 nM), effectively prevented the shift of activation (Table 1, Fig. 3). For these procedures, $\Delta E_{0.5}$ after BQ-123 alone and after BQ-123 plus ET-1 were insignificantly different from spontaneous shifts (see above).

\section{TTX-sensitive $\mathrm{Na}^{+}$currents are not modified by ET-1}

In seven larger cells, which have almost exclusively TTX-S sodium currents and minimal TTX-R, ET-1 had no effect on gating (Table 1). Activation midpoint potentials were $-17.3 \pm 0.2 \mathrm{mV}$ before ET-1, $-18.3 \pm 0.2 \mathrm{mV}$ after $5 \mathrm{~min}$, and $-18.8 \pm 0.2 \mathrm{mV}$ after 20 min exposures to ET-1 ( $p>0.15$ for the latter two values compared with pre-ET-1). $\chi^{2}$ analysis showed that the absence of a change in any of these seven cells is significantly different $(p<$ $0.025)$ than the presence of a shift in 10 of the 17 cells expressing TTX-R current.

\section{DISCUSSION}

\section{Relevance of this action to the pain-inducing behavior of ET-1}

These results define actions of ET-1 on sensory neurons that may explain the pain behavior and selective excitation of nociceptors that we observed in vivo (Davar et al., 1998; Fareed et al., 2000; Gokin et al., 2001). The dominant action of ET-1 is an $\mathrm{ET}_{\mathrm{A}}$

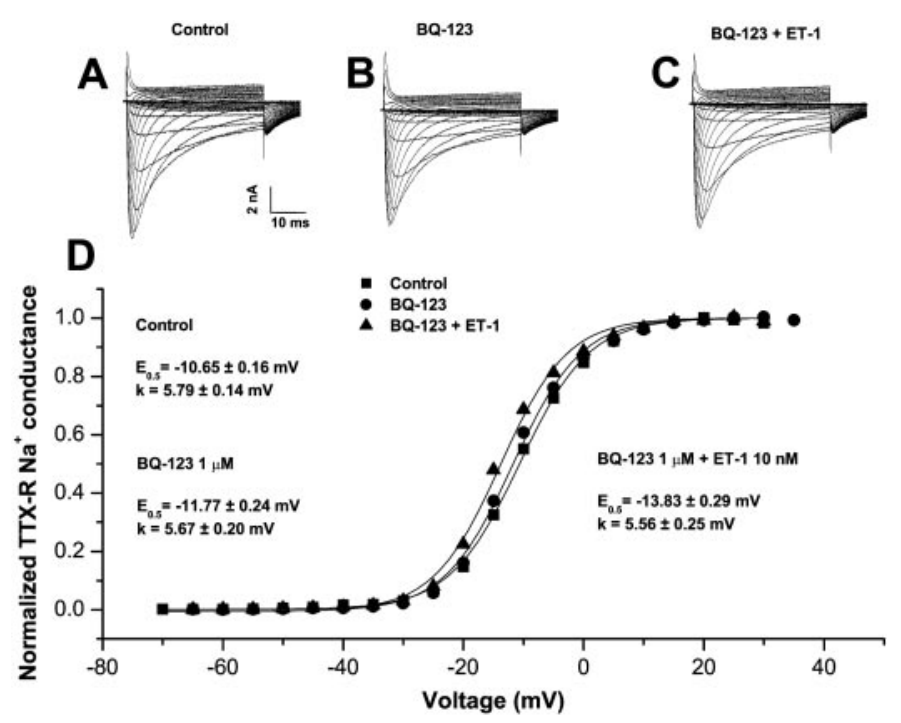

Figure 3. Changes in TTX-R activation induced by ET-1 are prevented by an $\mathrm{ET}_{\mathrm{A}}$ receptor antagonist. A family of control currents recorded in the same cell is shown before $(A), 10$ min after continuous exposure to the $\mathrm{ET}_{\mathrm{A}}$ receptor antagonist $\mathrm{BQ}-123(1 \mu \mathrm{M})(B)$, and after $10 \mathrm{~min}$ of additional exposure to BQ-123 $(1 \mu \mathrm{M})$ plus ET-1 (10 nM) $(C)$. Recording conditions were identical to those described in Figure 1. D, Boltzmann functions for the normalized peak conductance versus test potential from current data shown in $A-C$. Neither the activation midpoint nor the slope were modified by ET- 1 in the presence of BQ- 123 or by BQ-123 alone.

receptor-dependent shift in the hyperpolarizing direction for the voltage-dependent activation of TTX-R Na ${ }^{+}$channels, without any changes in TTX-S channels. Such shifts of TTX-R in the hyperpolarizing direction have also been described for other treatments that either sensitize nociceptors or induce pain (England et al., 1996; Gold et al., 1996; Kral et al., 1999; Cardenas et al., 2001). Because TTX-R currents represent several $\mathrm{Na}^{+}$channel subtypes, e.g., $\mathrm{Na}_{\mathrm{V}} 1.8$ and $\mathrm{Na}_{\mathrm{V}} 1.9$ (for alternate nomenclature, see Golden, 2001), found exclusively in small-diameter soma with nociceptor properties (Elliott and Elliott, 1993; Rush et al., 1998; Amaya et al., 2000; Fjell et al., 2000), these results are consistent with the specific activation by ET-1 of nociceptive afferents in vivo (Gokin et al., 2001). Differences in the response to ET-1 probably reflect heterogeneity in the distribution or availability of $\mathrm{ET}_{\mathrm{A}}$ receptors, or their downstream signals, rather than differences in the levels of or type of TTX-R currents (Rush et al., 1998). Although ET-1 has been shown to modulate ionic conductances in other excitable tissues (e.g., heart) (Lauer et al., 1992; Xie et al., 1996) through $\mathrm{ET}_{\mathrm{A}}$ and $\mathrm{ET}_{\mathrm{B}}$ receptors (Ono et al., 1994; Held et al., 1998; Boixel et al., 2001), this is the first report of an action of ET-1 on ion channels in the peripheral sensory nervous system.

\section{Importance of the shifts in TTX-R activation gating for sensory neuronal excitability}

These results raise the question of whether shifts in the activation gating of TTX-R produced by ET-1 are sufficient to induce impulses in responsive cells. In small-diameter DRG neurons with resting potentials of -50 to $-60 \mathrm{mV}$ (Wang et al., 1994; Study and Kral, 1996), the ET-1-induced changes in activation gating, approximately $-8 \mathrm{mV}$, would result in a modest additional $\mathrm{Na}^{+}$current. Given the known values of the resting resistance and capacitance of the soma, this seems unlikely to lead by itself to impulse generation. However, shifts in $\mathrm{Na}^{+}$activation can be 
at least twice as large in "intact" cells versus cells with modified intracellular content, as studied by the whole-cell method used here (Gold et al., 1996). Also, the "resting" membrane potential in cell soma may oscillate by several millivolts in amplitude; oscillations that are increased as the potential becomes less negative, appear to depend on $\mathrm{Na}^{+}$channels, and have been implicated in bursting ectopic discharges associated with pathologic pain (Amir et al., 1999). Furthermore, much higher concentrations of ET-1 than used here were applied in vivo to induce spontaneous firing, so that even larger shifts may be possible in vivo. Together, these factors could result in ET-1-induced shifts of the resting potential of $15-20 \mathrm{mV}$ (Herzog et al., 2001) and possible enhanced oscillations that alone could account for ET1-induced spike responses in cutaneous nociceptors (Gokin et al., 2001). ET-1 may also augment the responsiveness of neurons or sensory afferent terminals that are already receiving excitatory or even subthreshold stimuli.

\section{Identification of the $\mathrm{Na}^{+}$channel subtype involved}

At least two channels carry the TTX- $\mathrm{R} \mathrm{Na}^{+}$current in sensory neurons. These have been characterized variously by their activation midpoint potentials $\left(E_{0.5}\right)$, inactivation midpoint potentials $\left(h_{0.5}\right)$, and inactivation rates, although there is no consensus on these gating parameters. Here the peak $\mathrm{Na}^{+}$currents had control $E_{0.5}$ values of approximately $-14 \mathrm{mV}$ and $h_{0.5}$ values of approximately $-27 \mathrm{mV}$, identical to the values reported for so-called "TTX-R1" currents by Rush et al. (1998) and to the lumped TTX-R currents studied by others (Bossu and Feltz, 1984; England et al., 1996; Gold et al., 1996; Kral et al., 1999). Our analyses show that slowly inactivating TTX-R currents are altered much more by ET-1 than rapidly inactivating currents. This may reflect a differential sensitivity of channel isoforms, although we found no systematic difference in the $E_{0.5}$ or $h_{0.5}$ parameters between these more and less sensitive peak currents nor, for that matter, between currents in cells that responded to ET-1 and those that did not. Alternatively, the more rapidly inactivating currents may appear in cells with elevated pre-ET-1 exposure levels of a second messenger (e.g., cAMP), which leads to relatively faster channel inactivation as well as insensitivity to ET-1, as observed for 5-HT-induced changes in TTX-R (Cardenas et al., 2001).

Although we cannot discriminate in these experiments between the actions of ET-1 on different TTX-R channel subtypes, both of the described sensory neuron-specific TTX-R channels, $\mathrm{Na}_{\mathrm{v}} 1.8$ and $\mathrm{Na}_{\mathrm{v}} 1.9$, have been shown to play a critical role in neuronal excitability (Herzog et al., 2001; Renganathan et al., 2001). At this time, the only unequivocal assignment we can make is that more slowly inactivating TTX-R currents are the forms that respond strongly to ET-1 and that TTX-S currents are totally unaffected.

\section{REFERENCES}

Amaya F, Decosterd I, Samad TA, Plumpton C, Tate S, Mannion RJ, Costigan M, Woolf CJ (2000) Diversity of expression of the sensory neuron-specific TTX-resistant voltage-gated sodium ion channels SNS and SNS2. Mol Cell Neurosci 15:331-342.

Amir R, Michaelis M, Devor M (1999) Membrane potential oscillations in dorsal root ganglion neurons: role in normal electrogenesis and neuropathic pain. J Neurosci 19:8589-8596.

Armstrong CM, Bezanilla F (1977) Inactivation of the sodium channel. II. Gating current experiments. J Gen Physiol 70:567-590.

Boixel C, Dinanian S, Lang-Lazdunski L, Mercadier JJ, Hatem SN (2001) Characterization of effects of endothelin-1 on the L-type $\mathrm{Ca}^{2+}$ current in human atrial myocytes. Am J Physiol Heart Circ Physiol 281:H764-H773
Bossu JL, Feltz A (1984) Patch-clamp study of the tetrodotoxin-resistant sodium current in group C sensory neurones. Neurosci Lett 51:241-246. Cardenas LM, Cardenas CG, Scroggs RS (2001) 5HT Increases excitability of nociceptor-like rat dorsal root ganglion neurons via cAMPcoupled TTX-resistant $\mathrm{Na}^{+}$channels. J Neurophysiol 86:241-248.

Cheng TH, Chang CY, Wei J, Lin CI (1995) Effects of endothelin 1 on calcium and sodium currents in isolated human cardiac myocytes. Can J Physiol Pharmacol 73:1774-1783.

Cummins TR, Dib-Hajj SD, Black JA, Akopian AN, Wood JN, Waxman SG (1999) A novel persistent tetrodotoxin-resistant sodium current in small primary sensory neurons. J Neurosci 19:RC43(1-6).

Davar G, Hans G, Fareed MU, Sinnott C, Strichartz G (1998) Behavioral signs of acute pain produced by application of endothelin-1 to rat sciatic nerve. NeuroReport 9:2279-2283.

De-Melo JD, Tonussi CR, D'Orleans-Juste P, Rae GA (1998) Articular nociception induced by endothelin-1, carrageenan and LPS in naive and previously inflamed knee-joints in the rat: inhibition by endothelin receptor antagonists. Pain 77:261-269.

Elliott AA, Elliott JR (1993) Characterization of TTX-sensitive and TTX-resistant sodium currents in small cells from adult rat dorsal root ganglia. J Physiol (Lond) 463:39-56.

England S, Bevan S, Docherty RJ (1996) $\mathrm{PGE}_{2}$ modulates the tetrodotoxin-resistant sodium current in neonatal rat dorsal root ganglion neurones via the cyclic AMP-protein kinase A cascade. J Physiol (Lond) 495:429-440.

Fareed MU, Hans G, Atanda A, Strichartz G, Davar G (2000) Pharmacological characterization of acute pain behavior produced by application of endothelin-1 to rat sciatic nerve. Pain 1:46-53.

Ferreira SH, Romitelli M, de Nucci G (1989) Endothelin-1 participation in overt and inflammatory pain. J Cardiovasc Pharmacol 13 [Suppl 5]:S220-S222.

Fjell J, Hjelmstrom P, Hormuzdiar W, Milenkovic M, Aglieco F, Tyrrell L, Dib-Hajj S, Waxman SG, Black JA (2000) Localization of the tetrodotoxin-resistant sodium channel NaN in nociceptors. NeuroReport 11:199-202.

Gokin AP, Fareed MU, Pan H-L, Hans G, Strichartz GR, Davar G (2001) Local injection of endothelin-1 produces pain-like behavior and excitation of nociceptors in rats. J Neurosci 21:5358-5366.

Gold MS, Levine JD (1996) DAMGO inhibits prostaglandin E2-induced potentiation of a TTX-resistant $\mathrm{Na}^{+}$current in rat sensory neurons in vitro. Neurosci Lett 212:83-86.

Gold MS, Reichling DB, Shuster MJ, Levine JD (1996) Hyperalgesic agents increase a tetrodotoxin-resistant $\mathrm{Na}^{+}$current in nociceptors. Proc Natl Acad Sci USA 93:1108-1112.

Gold MS, Levine JD, Correa AM (1998) Modulation of TTX-R/I $I_{\mathrm{Na}}$ by $\mathrm{PKC}$ and PKA and their role in $\mathrm{PGE}_{2}$-induced sensitization of rat sensory neurons in vitro. J Neurosci 18:10345-10355.

Goldin AL (2001) Resurgence of sodium channel research. Annu Rev Physiol 63:871-894.

Graido-Gonzalez E, Doherty JC, Bergreen EW, Organ G, Telfer M, McMillen MA (1998) Plasma endothelin-1, cytokine, and prostaglandin E2 levels in sickle cell disease and acute vaso-occlusive sickle crisis. Blood 92:2551-2555.

Griswold DE, Douglas SA, Martin LD, Davis TG, Davis L, Ao Z, Luttmann MA, Pullen M, Nambi P, Hay DW, Ohlstein EH (1999) Endothelin B receptor modulates inflammatory pain and cutaneous inflammation. Mol Pharmacol 4:807-812.

Held B, Pocock JM, Pearson HA (1998) Endothelin-1 inhibits voltagesensitive $\mathrm{Ca}^{2+}$ channels in cultured rat cerebellar granule neurones via the ET-A receptor. Pflügers Arch 436:766-775.

Herzog RI, Cummins TR, Waxman SG (2001) Persistent TTX-resistant $\mathrm{Na}^{+}$current affects resting potential and response to depolarization in simulated spinal sensory neurons. J Neurophysiol 86:1351-1364.

Hille B (2001) Ionic channels of excitable membranes, Ed 3, p 58. Sunderland, MA: Sinauer.

Jarvis MF, Wessale JL, Zhu CZ, Lynch JJ, Dayton BD, Calzadilla SV, Padley RJ, Opgenorth TJ, Kowaluk EA (2000) ABT-627, an endothelin ET(A) receptor-selective antagonist, attenuates tactile allodynia in a diabetic rat model of neuropathic pain. Eur J Pharmacol 388:29-35.

Kerr BJ, Souslova V, McMahon SB, Wood JN (2001) A role for the TTX-resistant sodium channel Nav 1.8 in NGF-induced hyperalgesia, but not neuropathic pain. NeuroReport 12:3077-3080.

Kral MG, Xiong Z, Study RE (1999) Alteration of $\mathrm{Na}^{+}$currents in dorsal root ganglion neurons from rats with a painful neuropathy. Pain 81:15-24.

Lauer MR, Gunn MD, Clusin WT (1992) Endothelin activates voltagedependent $\mathrm{Ca}^{2+}$ current by a $\mathrm{G}$ protein-dependent mechanism in rabbit cardiac myocytes. J Physiol (Lond) 448:729-747.

Ono K, Tsujimoto G, Sakamoto A, Eto K, Masaki T, Ozaki Y, Satake M (1994) Endothelin-A receptor mediates cardiac inhibition by regulating calcium and potassium currents. Nature 370:301-304.

Piovezan AP, D'Orleans-Juste P, Tonussi CR, Rae GA (1997) Endothelins potentiate formalin-induced nociception and paw edema in mice. Can J Physiol Pharmacol 75:596-600.

Renganathan M, Cummins TR, Waxman SG (2001) Contribution of 
$\mathrm{Na}(\mathrm{v}) 1.8$ sodium channels to action potential electrogenesis in DRG neurons. J Neurophysiol 86:629-640.

Rush AM, Brau ME, Elliott AA, Elliott JR (1998) Electrophysiological properties of sodium current subtypes in small cells from adult rat dorsal root ganglia. J Physiol (Lond) 511:711-789.

Study RE, Kral MG (1996) Spontaneous action potential activity in isolated dorsal root ganglion neurons from rats with a painful neuropathy. Pain 65:235-242.

Wacnik PW, Eikmeier LJ, Ruggles TR, Ramnaraine ML, Walcheck BK, Beitz AJ, Wilcox GL (2001) Functional interactions between tumor and peripheral nerve: morphology, algogen identification, and behav- ioral characterization of a new murine model of cancer pain. J Neurosci 21:9355-9366.

Wang Z, Van den Berg RJ, Ypey DL (1994) Resting membrane potentials and excitability at different regions of rat dorsal root ganglion neurons in culture. Neuroscience 60:245-254

Xie LH, Horie M, James AF, Watanuki M, Sasayama S (1996) Endothelin-1 inhibits L-type Ca currents enhanced by isoproterenol in guinea-pig ventricular myocytes. Pflügers Arch 431:533-539.

Zhou Q-L, Strichartz G, Davar G (2001) Endothelin-1 activates ET $_{\mathrm{A}}$ receptors to increase intracellular calcium in model nociceptors. NeuroReport 12:3853-3857. 